\title{
PENINGKATAN KONDUKTIVITAS LITIUM BESI FOSFAT MELALUI PENAMBAHAN POLIANILINA TERDOPAN ASAM SULFAT
}

\author{
IMAN RAHAYU ${ }^{\ddagger 1}$, SUSAN SUSANTI ${ }^{1}$, ANNISA WIJAYATI $^{1}$, SAHRUL HIDAYAT $^{2}$ \\ ${ }^{I}$ Departemen Kimia, Fakultas Matematika dan Ilmu Pengetahuan Alam, UNPAD \\ ${ }^{2}$ Departemen Fisika, Fakultas Matematika dan Ilmu Pengetahuan Alam, UNPAD \\ Jalan Raya Bandung-Sumedang Km 21 Jatinangor, telepon/faximil (022)7794391
}

\begin{abstract}
Abstrak. $\mathrm{LiFePO}_{4}$ telah berhasil mengalami peningkatan konduktivitas melalui metode kimia konvensional dengan penambahan $\mathrm{H}_{2} \mathrm{SO}_{4}$ sebagai dopan pada polimer polianilina (PANI) dan penambahan serbuk PANI pada $\mathrm{LiFePO}_{4}$. Gugus fungsi dari $\mathrm{LiFePO}_{4}-\mathrm{PANI}$ berhasil diidentifikasi dengan FTIR. Morfologi dan komposisi unsur $\mathrm{LiFePO}_{4}-\mathrm{PANI}$ dikonfirmasi dengan pengamatan SEM-EDS. Nilai konduktivitas $\mathrm{LiFePO}_{4}$ yang ditambahkan PANI doping $\mathrm{H}_{2} \mathrm{SO}_{4} 6 \%$ mengalami peningkatan dari 4,052 S/cm menjadi 35,6332 S/cm berdasarkan metode four point probe.
\end{abstract}

Kata kunci : Polianilina, $\mathrm{LiFePO}_{4}$, doping, $\mathrm{H}_{2} \mathrm{SO}_{4}$, konduktivitas

Abstract. $\mathrm{LiFePO}_{4}$ have successfully been increased conductivity through conventional chemical methods with the addition of $\mathrm{H}_{2} \mathrm{SO}_{4}$ as a dopant in a polymer polianilina (PANI) and the addition of PANI on $\mathrm{LiFePO}_{4}$ powder. Functional groups of $\mathrm{LiFePO}_{4}$-PANI identified by FTIR. Morphology and elemental composition of $\mathrm{LiFePO}_{4}$-PANI was confirmed by SEM-EDS observation. $\mathrm{LiFePO}_{4}$ conductivity value added PANI doping $\mathrm{H}_{2} \mathrm{SO}_{4} 6 \%$ increase from $4.052 \mathrm{~S} / \mathrm{cm}$ to $35.6332 \mathrm{~S} / \mathrm{cm}$ by four-point probe method.

Keywords : Polyaniline, , $\mathrm{LiFePO}_{4}$, doping, $\mathrm{H}_{2} \mathrm{SO}_{4}$, conductivity

\section{Pendahuluan}

Baterai Litium menjadi baterai yang diunggulkan untuk masa mendatang, karena baterai ini mempunyai kapasitas yang besar, tahan lama, ringan dan ramah lingkungan. Baterai Litium banyak digunakan sebagai penyimpan energi untuk peralatan elekronik dan lebih menjanjikan dibandingkan baterai lain karena memiliki beda potensial yang tinggi, densitas energi tinggi, dan stabilitas siklus yang baik. $\mathrm{LiCoO}_{2}$ merupakan bahan katode yang umumnya dipakai untuk baterai ion Litium tetapi penggunaan $\mathrm{LiCoO}_{2}$ menyebabkan terjadinya pengurangan stabilitas setelah beberapa pemakaian dan juga kekurangan dari $\mathrm{LiCoO}_{2}$ adalah bersifat sangat toksik. Oleh karena itu diperlukan bahan katode lain yang lebih stabil dan lebih ramah lingkungan. Salah satu bahan katode yang dapat menggantikan penggunaan $\mathrm{LiCoO}_{2}$ adalah $\mathrm{LiFePO}_{4}$ yang memiliki stabilitas yang baik dan ramah lingkungan [1].

$\mathrm{LiFePO}_{4}$ sangat intensif dipelajari sebagai bahan katode untuk baterai Li-ion karena kapasitas teoretis tinggi $(170 \mathrm{mAh} / \mathrm{g})$, stabil, dan ramah lingkungan. Namun, tingkat kinerja yang kurang baik yaitu kemampuan yang dikaitkan dengan konduktivitas elektronik intrinsik yang rendah telah membatasi aplikasinya. Untuk meningkatkan konduktivitas elektronik yaitu dengan menambahkan dopan pada saat sintesis material katode, mencampur material katode dengan serbuk logam atau melapisi material katode dengan bahan yang konduktif seperti polianilina [2].

Polianilina (PANI) adalah salah satu bahan polimer konduktif yang mempunyai konduktivitas listrik yang relatif tinggi dan stabililitas lingkungan yang baik sehingga memiliki potensi aplikasi

* email : imanrahayu@yahoo.com 
yang luas. Bahan polimer konduktif ini sangat unik yaitu dapat mengalami perubahan sifat listrik dan optik yang reversibel melalui reaksi redoks dan doping-dedoping atau protonasi-deprotonasi sehingga sangat potensial dimanfaatkan pada berbagai aplikasi. Sejauh ini, bahan polianilina telah digunakan pada berbagai aplikasi seperti sensor kimia khususnya sensor gas, piranti elektronik, LED polimer dan baterai sekunder [3].

Dalam tulisan ini dilaporkan kegiatan sintesis polianilina dan karakterisasi gugus fungsi dan morfologi serta konduktivitas $\mathrm{LiFePO}_{4}$-PANI dengan penambahan asam sulfat sebagai dopan yang diharapkan dapat meningkatkan konduktivitas $\mathrm{LiFePO}_{4}$.

\section{Eksperimen}

Anilin yang akan digunakan terlebih dahulu dilakukan pemurnian dengan distilasi sehingga diperoleh anilin murni untuk proses polimerisasi. Proses polimerisasi anilin dapat dilakukan dengan cara mencampurkan $50 \mathrm{~mL}$ larutan $\mathrm{H}_{2} \mathrm{SO}_{4} 1 \mathrm{M}$ dengan $2 \mathrm{~mL}$ monomer anilin dan dilakukan pengadukan selama 1 jam menggunakan pengaduk magnetik. Sementara itu, dalam waktu yang bersamaan dilakukan pelarutan 6 gram amonium peroksidisulfat ke dalam $50 \mathrm{~mL}$ larutan $\mathrm{H}_{2} \mathrm{SO}_{4}$ $1 \mathrm{M}$ dan pengadukan dilakukan selama $1 \mathrm{jam}$. Pencampuran kedua larutan tersebut dilakukan dalam satu wadah kimia, kemudian dilakukan pengadukan selama 24 jam. Tahap selanjutnya yaitu penyaringan hasil polimerisasi dengan menggunakan corong Buchner kemudian pencucian dengan akuades dan metanol, dan dilakukan pengeringan dalam oven pada suhu $80^{\circ} \mathrm{C}$ selama 2 jam sehingga diperoleh endapan polimer. Endapan polimer yang diperoleh kemudian di undoping dengan penambahan $\mathrm{NH}_{4} \mathrm{OH} 0,1 \mathrm{M} 250 \mathrm{~mL}$, pengadukan dilakukan selama 1 jam, penyaringan dengan menggunakan corong Buchner, pencucian dilakukan dengan akuades dan metanol, dan pengeringan dilakukan dalam oven pada suhu $80^{\circ} \mathrm{C}$ selama $2 \mathrm{jam}$. Tahap selanjutnya yaitu proses plastisasi dan pendopingan variasi konsentrasi $\mathrm{H}_{2} \mathrm{SO}_{4}$ sehingga diperoleh konsentrasi dopan optimum. Pembuatan film $\mathrm{LiFePO}_{4}$-PANI dilakukan dengan mencampurkan $\mathrm{LiFePO}_{4}$ sebagai prekursor dan PANI sebagai polimer konduktif dengan komposisi persen berat 80:20, 60:40, 40:60, 20:80 dalam berat total 1 gram. Hasil pencampuran kemudian dimasukkan ke dalam $5 \mathrm{~mL}$ pelarut NMP sambil dilakukan pengadukan dengan pengaduk magnetic selama 16 jam dan dilakukan pencetakkan pada kaca berukuran $2 \times 2 \mathrm{~cm}$ kemudian dilakukan pengeringan dalam oven pada suhu $80^{\circ} \mathrm{C}$ selama 4 jam dan karakterisasi dilakukan dengan menggunakan FTIR, SEM-EDS dan metode four point probe.

\section{Hasil dan Pembahasan}

Data konduktivitas $\mathrm{LiFePO}_{4}$ terhadap konsentrasi dopan dan data konduktivitas $\mathrm{LiFePO}_{4}$ terhadap penambahan \% massa polianilina dengan konsentrasi dopan optimum ditunjukkan pada Gambar 1 dan Gambar 2.

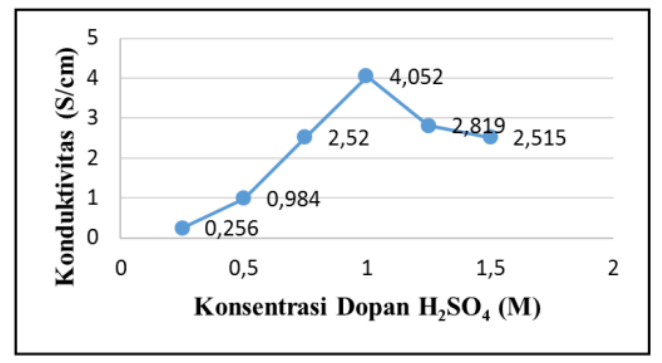

Gambar 1. Grafik data konduktivitas PANI terhadap variasi konsentrasi dopan $\mathrm{H}_{2} \mathrm{SO}_{4}$. 


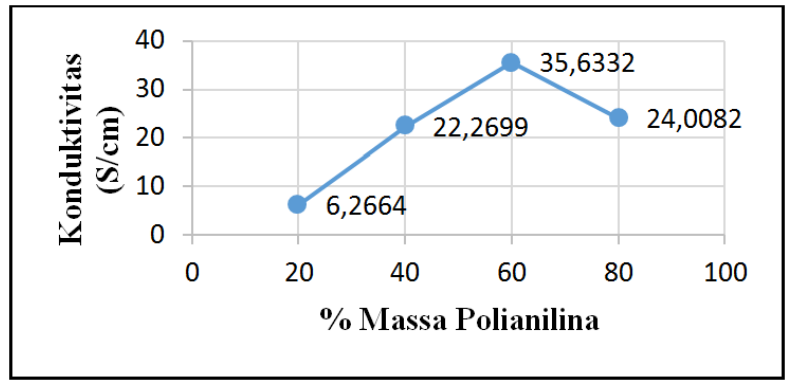

Gambar 2. Grafik data konduktivitas $\mathrm{LiFePO}_{4}$ terhadap penambahan $\%$ massa polianilina dengan dopan $\mathrm{H}_{2} \mathrm{SO}_{4}$

Gambar 1 merupakan data konduktivitas PANI terhadap variasi konsentrasi dopan $\mathrm{H}_{2} \mathrm{SO}_{4}$. Dari hasil pengukuran konduktivitas, terlihat adanya perubahan nilai konduktivitas pada tiap variasi konsentrasi dopan yang ditambahkan. Pada penambahan konsentrasi dopan $\mathrm{H}_{2} \mathrm{SO}_{4} 0,25 \mathrm{M}$ menghasilkan nilai konduktivitas yang masih rendah yaitu $0,256 \mathrm{~S} / \mathrm{cm}$, hal ini dikarenakan penambahan dopan yang masih sedikit. Pada penambahan konsentrasi dopan 0,5 M konduktivitas meningkat menjadi $0,984 \mathrm{~S} / \mathrm{cm}$ dan pada penambahan dopan 0,75 M memberikan nilai konduktivitas $2,52 \mathrm{~S} / \mathrm{cm}$ yang menunjukkan adanya peningkatan nilai konduktivitas. Pada penambahan konsentrasi dopan $1 \mathrm{M}$ terjadi peningkatan konduktivitas yang signifikan menjadi 4,052 S/cm. Pada penambahan konsentrasi dopan 1,25 M nilai konduktivitas mengalami penurunan menjadi 2,819 $\mathrm{S} / \mathrm{cm}$ sedangkan penambahan dopan 1,5 $\mathrm{M}$ menunjukkan nilai konduktivitas sebesar $2,515 \mathrm{~S} / \mathrm{cm}$. Hal ini disebabkan oleh rusaknya struktur rantai polimer karena konsentrasi asam yang diberikan terlalu tinggi sehingga terjadi penurunan konduktivitas PANI.

Gambar 2 menunjukkan data konduktivitas hasil dari pencampuran $\mathrm{LiFePO}_{4}$ dengan polianilina yang didoping dengan $\mathrm{H}_{2} \mathrm{SO}_{4}$. Dari grafik tersebut terlihat pada penambahan $20 \%$ massa polianilina menunjukkan konduktivitas yang masih rendah yaitu sebesar 6,2664 S/cm, konduktivitas yang masih rendah terjadi karena penambahan bahan aktif polianilina masih kurang banyak. Pada penambahan $40 \%$ massa polianilina, konduktivitas mulai meningkat yaitu sebesar $22,2699 \mathrm{~S} / \mathrm{cm}$. Kenaikan konduktivitas polianilina berlanjut sampai penambahan $60 \%$ massa polianilina dengan konduktivitas sebesar $35,6332 \mathrm{~S} / \mathrm{cm}$. Akan tetapi pada penambahan $80 \%$ massa polianilina konduktivitas menurun menjadi $24,0082 \mathrm{~S} / \mathrm{cm}$. Penurunan konduktivitas ini dapat disebabkan karena penambahan bahan aktif polianilina yang terlalu banyak yang melewati batas jenuh. Konduktivitas tertinggi dapat terukur pada penambahan massa polianilina $60 \%$ yaitu $35,6332 \mathrm{~S} / \mathrm{cm}$.

Uji gugus fungsi untuk $\mathrm{LiFePO}_{4}$-PANI doping $\mathrm{H}_{2} \mathrm{SO}_{4}$ dikonfirmasi berdasarkan pengamatan dari hasil analisis FTIR. Pada Gambar 3, tampak pita absorpsi pada panjang gelombang $605 \mathrm{~cm}^{-1}$ menunjukkan adanya ikatan $\mathrm{P}=\mathrm{O}$ yang merupakan serapan fosfat $\left(\mathrm{PO}_{4}{ }^{3-}\right)$ pada serbuk $\mathrm{LiFePO}_{4}$. Karakteristik polianilina ditunjukkan pada panjang gelombang $1560 \mathrm{~cm}^{-1}$ yang menunjukkan vibrasi regang $\mathrm{C}=\mathrm{C}$ dari cincin-cincin kuinoid $(\mathrm{N}=\mathrm{Q}=\mathrm{N})$ dan cincin-cincin benzoid (N-B-N) sebagai backbone polianilina. Karakteristik pada $1294 \mathrm{~cm}^{-1}$ bersesuaian dengan vibrasi regang CN. Puncak karakteristik pada $815 \mathrm{~cm}^{-1}$ merupakan vibrasi regang gugus amonium aromatik para subsitusi. Puncak kuat $1120 \mathrm{~cm}^{-1}$ merupakan regang $\mathrm{C}=\mathrm{N}$ cincin quinoid terprotonasi yang merupakan puncak karakteristik dari polianilina konduktif. Puncak karakteristik pada 1300-1350 $\mathrm{cm}^{-1}$ merupakan regang $\mathrm{S}=\mathrm{O}$ yang berasal dari sulfur. Puncak karakteristik pada $2410 \mathrm{~cm}^{-1}$ dan $2810 \mathrm{~cm}^{-1}$ merupakan regang $\mathrm{C}-\mathrm{H}$, dan puncak karakteristik pada bilangan gelombang $3300 \mathrm{~cm}^{-1}$ merupakan ikatan $\mathrm{O}-\mathrm{H}$. 


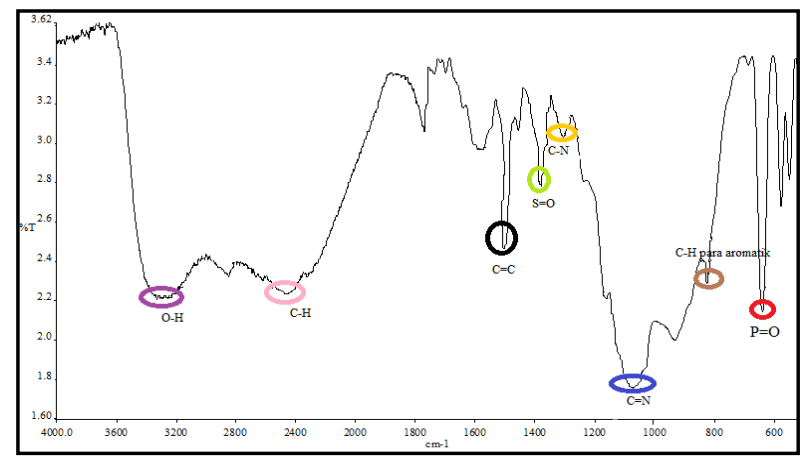

Gambar 3. Hasil karakterisasi film LiFePO4-PANI doping $\mathrm{H}_{2} \mathrm{SO}_{4}$.

Uji morfologi dan komposisi unsur dari $\mathrm{LiFePO}_{4}-\mathrm{PANI}$ dilakukan dengan menggunakan SEMEDS. Gambar 4 menunjukkan morfologi dari $\mathrm{LiFePO}_{4}$ murni pembesaran 5.000x (4.a) dan (4.c) $\mathrm{LiFePO}_{4}$ murni pembesaran 20.000x, dari gambar terlihat bahwa beberapa partikel $\mathrm{LiFePO}_{4}$ berbentuk granular dan butiran kecil yang menempel pada granular. Gambar (4.b) dan (4.d) menunjukkan pada $\mathrm{LiFePO}_{4}$-PANI yang didoping dengan $\mathrm{H}_{2} \mathrm{SO}_{4}$ terlihat membentuk agregat yang terdiri dari material granular. Penyebab terbentuknya agregat disebabkan dari adanya proses presipitasi.

Pada proses presipitasi terdapat gaya intermolekul yang merupakan gaya tarik-menarik antar molekul dan dampaknya dominan pada cairan maupun padatan. Secara umum, gaya intermolekul terdiri dari gaya dipol-dipol, dipol-semidipol dan gaya dispersi atau yang dikenal dengan gaya van der Waals. Gaya van der Waals akan semakin besar jika massa molar atau ukuran atom besar dimana elektron terluar akan semakin kurang terikat dengan inti sehingga mudah diganggu oleh molekul tetangganya. Saat endapan mengalami proses presipitasi, dalam keadaan tertentu, gaya van der Waals dapat menyebabkan ukuran partikel semakin besar atau yang disebut dengan peristiwa agregasi sehingga produk yang dihasilkan membentuk agregat. Adapun ukuran dari endapan dipengaruhi oleh beberapa variabel seperti kelarutan endapan, temperatur, konsentrasi reaktan, dan kecepatan pencampuran reaktan [4].

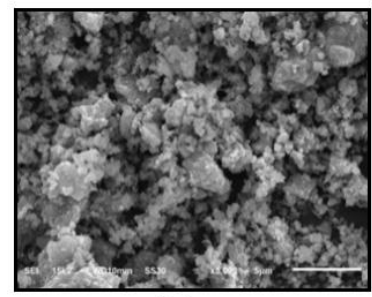

(a)

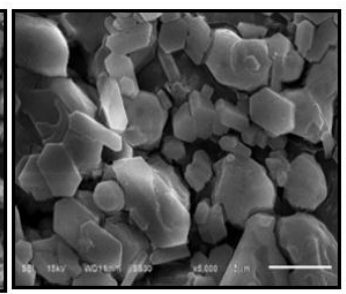

(b)

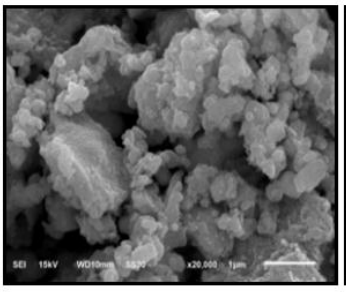

(c)

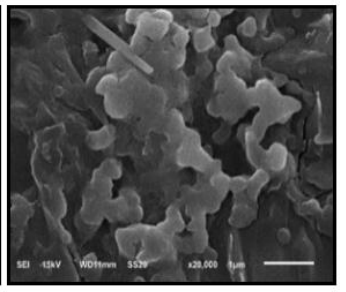

(d)

Gambar 4. Hasil foto SEM dari (a) LiFePO4 murni pembesaran 5.000x, (b) LiFePO4-PANI pembesaran 5.000x, (c) LiFePO4 murni pembesaran 20.000x , (d) LiFePO4-PANI pembesaran 20.000x.

Komposisi unsur komposit dari $\mathrm{LiFePO}_{4}$ dengan PANI yang didoping $\mathrm{H}_{2} \mathrm{SO}_{4}$ dapat diketahui dari pengukuran dengan menggunakan SEM-EDS. Hasil analisis komposisi unsur dari $\mathrm{LiFePO}_{4}$ dengan PANI ditunjukkan pada Gambar 5. Hasil analisis EDS dapat diketahui komposisi unsur-unsur diantaranya $13,55 \% \mathrm{C} ; 8,97 \% \mathrm{~N} ; 49,60 \% \mathrm{O} ; 0,79 \% \mathrm{P} ; 9,12 \% \mathrm{~S}$ dan 7,98\% Fe. Unsur nitrogen yang mewakili polianilina menunjukkan perolehan berat masih dibawah $20 \%$ dalam komposit 
LiFePO $-\mathrm{PANI}$ doping $\mathrm{H}_{2} \mathrm{SO}_{4}$. Hal ini diperkirakan $\left(\mathrm{NH}_{4}\right)_{2} \mathrm{~S}_{2} \mathrm{O}_{8(\text { aq })}$ tidak semuanya digunakan sebagai inisiator dalam proses polimerisasi polianilina tetapi juga digunakan untuk mengoksidasi $\mathrm{LiFePO}_{4(\mathrm{~s})}$ membentuk $\mathrm{FePO}_{4(\mathrm{~s})}[5]$
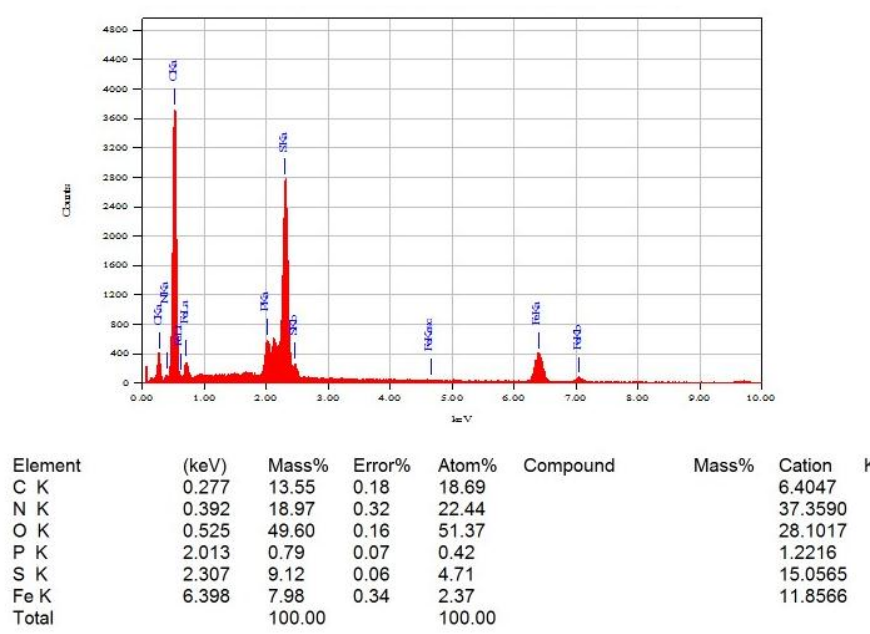

Gambar 5. Hasil SEM-EDS komposisi unsur komposit $\mathrm{LiFePO}_{4}-\mathrm{PANI}$ doping $\mathrm{H}_{2} \mathrm{SO}_{4}$.

\section{Kesimpulan}

Proses polimerisasi anilin melalui dengan penambahan $\mathrm{H}_{2} \mathrm{SO}_{4}$ meningkatkan konduktivitas $\mathrm{LiFePO}$. Penambahan dopan pada polianilina berpengaruh terhadap konduktivitas dari $\mathrm{LiFePO}_{4}$. Nilai konduktivitas meningkat pada perbandingan (PANI-EB:LiFePO $\left.{ }_{4}\right) 60 \%$ dari 4,052 S/cm menjadi 35,6332 S/cm. Hal ini diperkuat dengan adanya gugus fungsional $\mathrm{LiFePO}_{4}-\mathrm{PANI}$ dari hasil pengamatan FTIR, morfologi permukaan, dan komposisi unsur dari $\mathrm{LiFePO}_{4}$ - PANI yang dianalisis dengan menggunakan SEM-EDS.

\section{Daftar Pustaka}

1. Stefania, P., Scorasti, B., Wachtler, M., Croce, F. 2009. Natotechnology for the progres of lithium batteries. Journal of Power Sourches. Vol. 146, pp. 793-797.

2. Maddu, A., Wahyudi, S., Kurniati, M. 2008. Sintesis dan Karakterisasi Nanoserat Polianilina. Skripsi. Bogor. Departemen Fisika FMIPA Institut Pertanian Bogor.

3. Zhang, W.M., Hu, J.S., Guo, Y.G., Zheng, S.F., Zhong, L.S., Wan, L.J. 2012. Preparation and Characterization of $\mathrm{FeS}_{2}$ /Polyaniline Composite Electrode in Lithium Ion Battery. Journal of The Australian Ceramic Society. Vol. 48, pp. 189-193.

4. Pisesa, M. 2009. Sintesis Polianilin dan Modifikasinya dengan $\mathrm{H}_{2} \mathrm{SO}_{4}$ pekat untuk Identifikasi Formalin. Tesis. Depok: Kimia FMIPA UI.

5. Li, D., Huang, J., Kaner, R.B. 2009. Polyaniline Nanofibers: A Unique Polymer Nanostructure For Versatile Applications. Acc. Chem. Res. Vol. 42, pp. 135-145. 